\title{
Isocordoin Derivatives From the Root Extract of Lonchocarpus xuul
}

\author{
Alejandro Yam-Puc and Luis M. Peña-Rodríguez ${ }^{1 *}$ \\ 1 Grupo de Química Orgánica, Unidad de Biotecnología, Centro de Investigación Científica de Yucatán, Calle 43 No. 130 , \\ Colonia Chuburná, Mérida, Yucatán, México.1manuel@cicy.mx
}

Received October 27, 2008; accepted February 25, 2009

\begin{abstract}
Two natural isocordoin derivatives, dihydroisocordoin (1) and flemistrictin B (2), were isolated from the root extract of Lonchocarpus xuul. Both metabolites were identified on the basis of their spectroscopic data and by comparing them with those reported in the literature.

Key words: Lonchocarpus xuul, Leguminosae, Chalcones, Dihydroisocordoin, Flemistrictin B.
\end{abstract}

\section{Introduction}

Lonchocarpus xuul Lundell (Leguminosae) is a tree endemic to the Yucatan Peninsula, which is known as "xuul", "kanxuul" or "yaax-xuul". Previous phytochemical studies of L. xuul have resulted in the isolation and identification of a number of flavonoids (e.g. chalcones, flavones, flavans, pyranoflavans, flavanones), including the two novel flavans xuulanin and $3 \beta$-methoxy-xuulanin, and the known flavanone spinoflavanone-B. [1-3] In our continuing search for novel secondary metabolites from Yucatecan native plants, we wish to report herein on the isolation and identification of two additional isocordoin derivatives from the root extract of $L$. xuul Lundell.

\section{Results and Discussion}

Successive chromatographic purifications of the hexane root extract of L. xuul, using a combination of VLC, gravity column chromatography and gel filtration on Sephadex LH-20, resulted in the isolation of metabolites $\mathbf{1}$ and $\mathbf{2}$ in pure form.

The less polar metabolite $\mathbf{1}$ was obtained as colorless oil. The parent ion peak at $\mathrm{m} / \mathrm{z} 310$ of its mass spectrum suggested a molecular formula of $\mathrm{C}_{20} \mathrm{H}_{22} \mathrm{O}_{3}$, which in turn indicated the presence of ten unsaturation sites in the structure. The IR spectrum of 1 exhibited strong absorption bands for hydroxyl (3421 $\left.\mathrm{cm}^{-1}\right)$ and carbonyl $\left(1613 \mathrm{~cm}^{-1}\right)$ groups. The ${ }^{1} \mathrm{H} \mathrm{NMR}$ spectrum of 1 showed a number of signals that suggested an isocordoin-type structure, namely two one-proton signals at $6.35\left(\mathrm{H}-5^{\prime}, d, 8.8\right)$ and $7.54\left(\mathrm{H}^{-6}{ }^{\prime}, d, 8.8\right)$, corresponding to the two ortho-coupled protons of a 1,2,3,4 tetrasubstituted aromatic ring, and two multiplets at $7.30(2 \mathrm{H})$ and $7.25(3 \mathrm{H})$, corresponding to the five protons of a second, monosubstituted, aromatic ring. While the monosusbstituted nature of the aromatic ring was further confirmed by the fragment ion peak at $\mathrm{m} / \mathrm{z} 77$ in the mass spectrum of $\mathbf{1}$, a chelated hydroxyl-proton
Resumen: Del extracto de la raíz de Lonchocarpus xuul fueron aislados dos derivados naturales de isocordoína, dihidroisocordoína (1) y flemistrictina B (2). Ambos metabolitos fueron identificados con base en sus datos espectroscópicos y por comparación de los mismos con los reportados en la liberatura.

Palabras clave: Lonchocarpus xuul, leguminosa, chalcones, dihidroisocordoína, flemistrictina B.

signal at 13.14 , together with a chelated carbonyl-carbon resonance at d 203.92, were consistent with a 2'-hydroxychalconetype structure [4]. However, unlike isocordoin, the ${ }^{1} \mathrm{H}$ NMR spectrum of metabolite $\mathbf{1}$ did not show the two one-proton signals of the trans-olefinic protons assigned to $\alpha$ and $\beta$ positions of the unsaturated ketone system; instead, two methylene signals at $3.04(2 \mathrm{H}, t, 7.7)$ and $3.24(2 \mathrm{H}, t, 7.7)$ were observed. Accordingly, the IR spectrum of $\mathbf{1}$ did not show an absorption band characteristic of a conjugated carbonyl system and the observed molecular ion peak at $\mathrm{m} / \mathrm{z} 310$ of $\mathbf{1}$, indicated one less unsaturation site in the molecular structure when compared to that of isocordoin. Finally, the observed fragment ions at $\mathrm{m} / \mathrm{z}$ 105 and 91 in the MS of 1 confirmed a dihydrochalcone-type structure [5]. On the basis of its spectroscopic data, metabolite 1 was identified as dihydroisocordoin, a dihydrochalcone previously reported as an intermediate in the semisynthesis of tetrahydroflemichapparin-A [6], and recently reported as erioschalcone B, a novel bioactive (antimicrobial) natural product from Eriosema glomerata [7].

Metabolite $\mathbf{2}$ was isolated as a yellow oil, which appeared as an intense deep brown spot when run on TLC and observed under UV light. The HR-EIMS of $\mathbf{2}$ indicated a molecular formula $\mathrm{C}_{20} \mathrm{H}_{20} \mathrm{O}_{4}$, suggesting an isocordoin-type structure

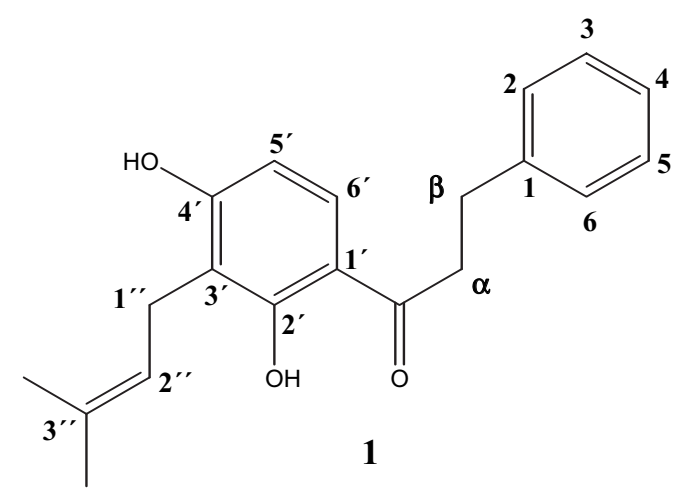


with an extra oxygen atom. Accordingly, the IR spectrum of $\mathbf{2}$ showed the isocordoin-characteristic absorption bands at 3472 (hydroxyl) 1639 (carbonyl) and 1592 (aromatic) $\mathrm{cm}^{-1}$, and its ${ }^{1} \mathrm{H}$ NMR showed the expected signals for a chalcone, including the protons corresponding to both a monosubstituted and a tetrasubstituted aromatic rings and those corresponding to the protons of a trans double bond $[\mathrm{H}-\alpha$ at $7.57 \mathrm{ppm}(d, 15.6)$ and $\mathrm{H}-\beta$ at $7.86 \mathrm{ppm}(d, 15.6)]$ and a hydrogen-bonded phenol group (13.40 ppm, $s$ ). The main difference between the ${ }^{1} \mathrm{H}$ NMR spectrum of $\mathbf{2}$ and that of isocordoin was the absence of the signals corresponding to the prenylated chain, and the presence of an oxygenated methine-proton signal at $4.78 \mathrm{ppm}$ $(d d, 8.4,9.6)$. The presence of additional signals corresponding to a methylene $(3.16 \mathrm{ppm}, \mathrm{m})$ and to a gem-dimethyl group [1.24 (s) and $1.35 \mathrm{ppm}(\mathrm{s})]$ in the ${ }^{1} \mathrm{H}$ NMR spectrum of 2, together with a quaternary carbon signal at $71.91 \mathrm{ppm}$ in its ${ }^{13} \mathrm{C}$ NMR spectrum, allowed the identification of an isopropyloxi dihydrofuran moiety in the structure of $2[8,9]$. The formation of a monoacetylated derivative, upon treatment of 2 with acetic anhydride-pyridine, confirmed the presence of a tertiary alcohol in the structure. Similarly, the correlation observed, in the HMBC experiment of $\mathbf{2}$, between the oxymethine proton (H2") and the phenolic carbon (C-4'), together with the hydrogen-bonded phenol group $(13.40 \mathrm{ppm}, s)$ in the ${ }^{1} \mathrm{H}$ NMR spectrum, confirmed the arrangement of the dihydrofuran ring. The spectroscopic data of metabolite 2 proved to be identical to those reported for flemistrictin $\mathrm{B}$, a chalcone isolated from the leaves of Flemingia stricta [5] and the seeds of Lonchocarpus sericeus [10]. It is interesting to mention that, to date, the stereochemistry at C-2" of flemistrictin B has not been reported; this is probably due to the fact that 2 appears to occur naturally as a racemic mixture, resulting from the non-stereospecific cyclization between the phenolic hydroxyl group at C-4' and the epoxidated prenylated chain at C-3', as suggested by the very small value $(+3.3)$ of its optical rotation.

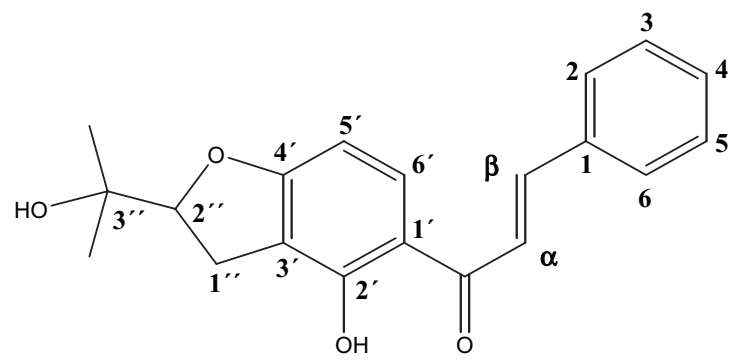

2

\section{Experimental section}

\section{General Experimental Procedures}

Vacuum Liquid Chromatography (VLC) and column chromatography purifications were performed using E.M. Merck
TLC-grade silica gel $60_{\mathrm{GF}}$ and E.M. Merck silica gel (70-230 mesh), respectively. Gel permeation column chromatography purifications were carried out using Sephadex LH-20 (Sigma, size 25-100). Analytical TLC analyses were carried out using aluminum-backed silica gel $\left(60 \mathrm{~F}_{254}\right)$ plates (E.M. Merck, 0.2 $\mathrm{mm}$ thickness); the plates were first examined under UV light ( $\lambda 254$ and $366 \mathrm{~nm}$ ) and the various components in the chromatograms were visualized by dipping the plates in a solution of phosphomolybdic acid $(20 \mathrm{~g})$ and ceric sulfate $(2.5 \mathrm{~g})$ in $500 \mathrm{~mL}$ of sulfuric acid (5\%), followed by drying and gentle heating. The optical rotation was measured in $\mathrm{CHCl}_{3}$ using a Perkin Elmer 341 polarimeter. IR spectra were recorded in $\mathrm{CHCl}_{3}$ (film) using an FT-Nicolet Magna Protégé 460 spectrophotometer. ${ }^{1} \mathrm{H}$ NMR $(400 \mathrm{MHz})$ and ${ }^{13} \mathrm{C}$ NMR $(100 \mathrm{MHz})$ spectra were obtained in $\mathrm{CDCl}_{3}$, on a Bruker Avance 400 spectrometer, using the residual $\mathrm{CHCl}_{3}$ signal $(7.26$ and $77.00 \mathrm{ppm}$ for ${ }^{1} \mathrm{H}$ and ${ }^{13} \mathrm{C}$, respectively) as reference. $\mathrm{GC}$ analyses were run on a Hewlett Packard 5890 gas chromatograph [GC conditions: split injection of $1 \mu \mathrm{L}$ of sample; Ultra 1 column $(25 \mathrm{~m}$ $\times 0.2 \mathrm{~mm}$ i.d.), flow rate $1.0 \mathrm{~mL} / \mathrm{min}$ (Nitrogen); oven temperature program $T_{1}=180^{\circ} \mathrm{C}(3 \mathrm{~min}), T_{2}=280^{\circ} \mathrm{C}(15 \mathrm{~min})$, gradient $10^{\circ} \mathrm{C} / \mathrm{min}$, injector $300^{\circ}$ and detector (FID) $300^{\circ} \mathrm{C}$. Mass spectra were performed with a JEOL-JMS-SX102 and ESI-HRMS (Electro-Spray Ionization Mass with the Waters Q-TOF microsystem) using $0.1 \%$ phosphoric acid in a $1: 1$ water/acetonitrile mixture as reference.

\section{Plant material}

The roots of $L$. xuul were collected in September 2007 from plants growing in a field located at $\mathrm{km} 6$ of the Libre UniónYaxcabá highway in Yucatán, Mexico. A voucher specimen has been deposited at the herbarium of "Unidad de Recursos Naturales CICY", under the collection number 1089. The plant material was washed with tap water and dried, first for a week at room temperature, and then for $72 \mathrm{~h}$ in an oven at $55^{\circ} \mathrm{C}$.

\section{Extraction and isolation}

The dry and ground roots $(1.8 \mathrm{~kg})$ were extracted four times with hexane at room temperature; the solution was filtered and evaporated to produce $11.5 \mathrm{~g}$ of crude hexane extract, which was subjected to VLC purification, eluting with increasing amounts of acetone in hexane to produce four main fractions. Fraction 3 was further purified by VLC, again using a gradient elution with hexane-acetone mixtures. Successive purifications using gravity column chromatography (benzene $100 \%$, followed by hexane/acetone 9:1 and 8:2) and Sephadex LH-20 $(\mathrm{MeOH})$, resulted in the isolation of $\mathbf{1}(10 \mathrm{mg})$ and $\mathbf{2}(40 \mathrm{mg})$ in pure form.

\section{Dihydroisocordoin (1)}

Colorless oil; soluble in $\mathrm{CHCl}_{3}$ and EtOAc. $\mathrm{R}_{f} 0.35$ in hexaneacetone 9:1. $\mathrm{t}_{R}(\mathrm{GC})=12.89 \mathrm{~min}$. IR $\left(\mathrm{CHCl}_{3}, \mathrm{film}\right): 3421 \mathrm{~cm}^{-1}$ (OH), $2924 \mathrm{~cm}^{-1}(\mathrm{C}-\mathrm{H})$, and $1613 \mathrm{~cm}^{-1}(\mathrm{C}=\mathrm{O})$. MS m/z 310.2 
$\left[\mathrm{M}^{+}\right.$]. ${ }^{1} \mathrm{H}$ NMR $\left(\mathrm{CDCl}_{3}, 400 \mathrm{MHz}\right) \delta 7.30(2 \mathrm{H}, \mathrm{m}, \mathrm{H}-2 / \mathrm{H}-6)$, $7.25(3 \mathrm{H}, \mathrm{m}, \mathrm{H}-3,4,5), 6.35(1 \mathrm{H}, \mathrm{d}, J=8.8, \mathrm{H}-5$ ') $7.54(1 \mathrm{H}$, d, $J=8.8, \mathrm{H}-6$ '), 3.44 (2H, da, $J=7.1, \mathrm{H}-1$ " $), 5.26$ (1H, tt, $J=$ 1.3, 6.1, H-2" ), $1.76\left(3 \mathrm{H}, \mathrm{s}, \mathrm{CH}_{3}\right), 1.82\left(3 \mathrm{H}, \mathrm{s}, \mathrm{CH}_{3}\right), 3.24(2 \mathrm{H}$, $\mathrm{t}, J=7.7, \mathrm{H} \alpha), 3.04$ (2H, t, $J=7.7, \mathrm{H} \beta), 6.06$ (1H, s, OH-4'), 13.14 (1H, s, OH-2'); ${ }^{13} \mathrm{C}$ NMR $\left(\mathrm{CDCl}_{3}, 100 \mathrm{MHz}\right) \delta 141.1$ (C-1), 128.5 (C-2/C-6), 128.7 (C-3/C-5), 126.4 (C-4), 113.4 (C-1'), 162.8 (C-2'), 114.1 (C-3'), 161.5 (C-4'), 107.9 (C-5'), 129.6 (C-6'), 21.8 (C-1"), 121.1 (C-2”), 136.1 (C-3"), 26.0 $\left(\mathrm{CH}_{3}\right), 18.1\left(\mathrm{CH}_{3}\right), 39.8(\mathrm{C} \alpha), 30.6(\mathrm{C} \beta), 203.9(\mathrm{C}=\mathrm{O})$.

\section{Flemistrictin B (2)}

Yellow oil, soluble in $\mathrm{CHCl}_{3}$ and EtOAc. $\mathrm{R}_{f} 0.17$ in hexane-

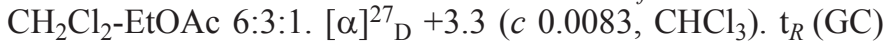
$=15.33 \mathrm{~min}$. IR $\left(\mathrm{CHCl}_{3}\right.$, film): $3472 \mathrm{~cm}^{-1}(\mathrm{OH}), 2939 \mathrm{~cm}^{-1}$, $2975 \mathrm{~cm}^{-1}(\mathrm{C}-\mathrm{H}), 1639 \mathrm{~cm}^{-1}(\mathrm{C}=\mathrm{O})$ and $1592(\mathrm{C}-\mathrm{H}$, aromatic ring). HRESIMS m/z $325.1440\left[\mathrm{M}^{+}+\mathrm{H}\right]$ (calcd for $\mathrm{C}_{20} \mathrm{H}_{21} \mathrm{O}_{4}$ : 325.1439). ${ }^{1} \mathrm{H} \mathrm{NMR}\left(\mathrm{CDCl}_{3}, 400 \mathrm{MHz}\right) \delta 7.64(2 \mathrm{H}, \mathrm{m}, \mathrm{H}-2 / \mathrm{H}-$ 6), 7.42 (3H, m, H-3,4,5), 6.44 (1H, d, $J=8.8, \mathrm{H}-5$ ') $7.80(1 \mathrm{H}$, d, $J=8.8, \mathrm{H}-6$ '), 4.78 (1H, dd, $J=8.4,9.6, \mathrm{H}-2$ '”), $3.16(2 \mathrm{H}$, m, H-1"), $1.24\left(3 \mathrm{H}, \mathrm{s}, \mathrm{CH}_{3}\right), 1.35\left(3 \mathrm{H}, \mathrm{s}, \mathrm{CH}_{3}\right), 7.57(1 \mathrm{H}, \mathrm{d}$, $J=15.6, \mathrm{H} \alpha), 7.86(1 \mathrm{H}, \mathrm{d}, J=15.6, \mathrm{H} \beta), 13.40$ (1H, s, OH-2'); ${ }^{13} \mathrm{C} \mathrm{NMR}\left(\mathrm{CDCl}_{3}, 100 \mathrm{MHz}\right) \delta 134.8(\mathrm{C}-1), 128.5(\mathrm{C}-2 / \mathrm{C}-6)$, 128.9 (C-3/C-5), 130.6 (C-4), 113.8 (C-1'), 161.5 (C-2'), 114.9 (C-3'), 166.7 (C-4'), 101.8 (C-5'), 131.9 ( C-6'), 91.7 (C-2”'), 27.3 (C-1"), 71.9 (C-3”), $23.8\left(\mathrm{CH}_{3}\right), 25.9\left(\mathrm{CH}_{3}\right), 120.5(\mathrm{C \alpha})$, $144.2(\mathrm{C} \beta), 192.0(\mathrm{C}=\mathrm{O})$.

\section{Acknowledgements}

The authors wish to thank Rocío Borges-Argáez for providing an isocordoin-rich fraction for initial purification, and Mirbella Cáceres-Farfán for technical assistance. The results of this investigation are part of the RIBIOFAR-CYTED project. Financial support from FOMIX-Yucatán (grant No. YUC2006-C05-66262) is also gratefully acknowledged.

\section{References}

1. Borges-Argáez, R.; Peña-Rodríguez, L. M.; Waterman, P. G. Phytochem. 2002, 60, 533-540.

2. Borges-Argáez, R.; Peña-Rodríguez, L. M.; Waterman, P. G. Phytochem. 2000, 54, 611-614.

3. Borges-Argáez, R.; Poot-Díaz, M. E.; Waterman, P. G.; PeñaRodríguez, L. M. J. Braz. Chem. Soc. 2005, 16, 1078-1081.

4. Abegaz, B. M.; Ngadjui, B. T.; Dongo, E.; Ngameni, B.; Nindi, M. N.; Bezabih, M. Phytochem. 2002, 59, 877-883.

5. Subrahmanyam, K.; Madhusudhana-Rao, J.; Vemuri, V. S. S.; Sivaram-Bacu, S.; Roy, C. P.; Jagannadha, Rao K. V. Indian J. Chem. 1982, 21, 895-897.

6. Adityachaudhury, N.; Chowdhury, A.; Kirtaniya C. L.; Chatterjee, A.; Chem. Ind. (London). 1975, 179-180.

7. Awouafack, M.D.; Kouam, S.F.; Hussain, H.; Ngamga, D.; Tane, P.; Schulz, B.; Green, I.R.; Krohn, K. Planta Med.. 2008, 74, 5054.

8. Narváez-Mastache, J. M.; Garduño-Ramírez, M. L.; Álvarez, L.; Delgado, G. J. Nat. Prod. 2006, 69, 1687-1691.

9. Veitch, N.C.; Grayer, R.J. In Flavonoids. Chemistry, Biochemistry and Applications; Andersen, O.M.; Markham, K.R., eds.; Taylor \& Francis: Boca Raton, FL, 2006, ch. 16.

10. Mahmoud, E.-H.N.; Waterman, P.G. J. Nat. Prod. 1986, 49, 11791180 . 